\title{
東拉西扯也談中日文化差異 \\ Let's gossip about the difference between Chinese and Japanese culture
}

\section{李 澤森 \\ 第一日語暨文化學校}

中國和日本, 一衣帶水, 同樣是漢字文化圈的國家, 雖然如此, 兩個民族之間還是存有某程度上 的文化差異, 了解雙方文化上的異同, 也許可以化解歷史上遺留下來的紛爭。

\section{1.《同文異義》}

有人說中國人和日本人同文同種, 是否同種暫且不說, 在所謂同文方面, 意思上大相逕庭的漢字 詞彙不少。好像日文的「情報」, 一般解作消息、信息, 但中文則是諜報的意思, 非同小可。日文的 「ご検討のほど、よろしくお願いいたします」裡的「検討」, 意為希望對方加以探討, 然後給予方 便, 但中文則是要對方好好反省的意思。中文的「風俗」指習俗、禮節或風尚, 但日文的「風俗」則 跟情色有關。「風俗事業」指「色情行業」, 「風俗犯罪」指風化案。日文「適当」一詞, 除了解作 $「$ 恰當」、「適度」之外, 還有「隨便」、「敷衍」的意思, 這是使用同一漢字詞彙的中國人難以想 像的。此外, 日文的「接客」可能令中國人想入非非。還有, 如果把「1 階の受付カウンターの前で お待ちください。」、「先生に注意されました。」裡的「1 階」和「注意」原封不動地譯作「一 樓」和「注意」或「小心」, 說不定會引起不必要的誤會。

\section{2. 《觀念和概念》}

中文的「滑」、「乾」、「濕」、「肥」、「瘦」都是形容詞, 但日文的「滑る」、「乾く」、 「湿る」、「太る」、「瘦せる」卻是動詞, 這反映彼此的觀念不同。

日本人視龜為吉祥物, 象徵長壽, 有「鶴は千年、亀は万年」之說。當今的中國人卻視這個古代 圖騰之一的烏匽為王八, 「龜公」、「龜蛋」都不是好東西。

中國人視狐為妖莩, 狐狸精是搶人家丈夫的女人, 九尾狐是專門幻化成絕世美女迷惑君王的妖 怪。在日本, 雖然也有「人狐」、「おとら狐」等妖怪, 但狐也不盡是壞蛋, 兒童民學家新美南吉在 「ごん狐」中描述的頑皮小狐就是善者的化身。狐也被視作耕作之神稻荷的使者, 所以, 各地的稻荷 神社也有供奉狐仙。

日本的社會風氣比中國開放, 但對紋身還是有所保留, 日本一些澡堂和泳池都明文規定不歡迎有 紋身的人士內進, 這點似乎較中國人更為保守。 
在「大」和「小」的概念上, 中國人和日本人有時也不盡相同。中國人說「大船」、「小船」, 日本人也會說「大きい船」、「小さい船」。中國人說「大碼」、「小碼」, 日本人也會說「大きい サイズ」、「小さいサイズ」。可是中國人說「這個世界很小」, 日本人很少會說「この世界は小さ い」, 反而會說「狭い」, 同樣地, 這個世界很大, 日本人大多會說「この世界は広い」而不會說 「大きい」。中國人說眼睛大, 日本人也會說「目が大きい」，但眼睛小，日本人大多只會說「目が 細い」。

日本和中國一樣, 中央政府之下, 還有地方政府, 在中國, 最大的地方自治體是省、自治區和直 轄市, 然後依次是市、縣、鄉、鎮、村。日本則以都道府縣為最大地方自治體, 然後依次是市、町、 村。在中國市級政府高於縣級政府, 但在日本則相反。

對日本人來說, 他們可能覺得中國人說的北京市市長、廣東省省長十分累贅, 同樣地中國人也很 不習慣日本人只說「庶務部長」、「事務所長」。

\section{3. 《生活細節和飲食習慣》}

不少初到香港的日本人都會抱怨香港缺少了公共廝所, 這是完全沒有因為找不到公廁而煩惱的香 港人難以理解的。反而, 到日本去的香港人很多時會因為在東京街頭找不到廢紙箱而感到十分不便。 對他們提倡的「ゴミは持ち帰りましょう」、「自分が出したゴミは持ち帰るのが最低限のマナーで す。」感到難以理喻。

在日本, 大家都遵守不在火車車廂裡打電話這個約定俗成的禮儀, 但在香港, 日本人也會入鄉隨 俗, 在公共汽車或地鐵車廂內大模斯樣地使用手提電話跟別人通話。

在辦公室禮儀方面, 不少香港人都習以為常地回到辦公室才吃買回來的早餐, 但日本人上司往往 看在眼裡, 氣在心頭。還有, 除非逼不得已, 日本人很少打擾正在接待來客的同事, 但香港人則覺得 反正都是公事, 不管同事正忙於應對眼前的客人或是接聽電話, 也照樣吩咐這吩咐那, 甚至插科打 諢。

日本人對中國豎起拇指和尾指, 再把其餘三只手指屈向手心表示數目「六」的手勢難以理解, 因 為在日本, 拇指表示男性或男朋友, 尾指表示女性或女朋友。日本人是以右手食指放在張開的左手手 心來表示「六」的數目的。不過, 如果日本人以黏有唾液的手指作勢擦在眉毛上, 這下子可得小心了, 因為他在暗示某人是「まゆつばもの」, 並不可靠。

在飲食習慣方面, 大多數日本人對於動物的內臟都敬而遠之, 他們大多不了解中國人以形補形的 飲食習慣, 甚至覺得既野且蠻。但中國人反而會覺得嘹吃生魚片的大和民族還沒開化。除了生魚片之 外, 日本人認為生菜、卷心菜 (廣東人叫椰菜)、青瓜等生吃較為可口。

中國人和日本人都使用筷子進食, 據考究, 直至五代十國為止, 中國人都習慣把筷子横放, 而這 個擺放方式也傳至日本。後來, 由於受外族的飲食文化影響, 使用筷子之餘, 也使用刀, 為了使用上 的方便而把刀和筷都直放, 直至現在。 
不少中國人和日本人都好杯中物, 暢飲時大家都會說「乾杯」, 但中國人的「乾杯」是一飲而盡 的, 日本人則是淺嚐即止。

\section{4. 《冠婚葬祭・紅白二事》}

日本人很重視「冠婚葬祭」, 中國人也很重視紅白二事, 但相對於中國式的鼎沸喧鬧, 日本人的 婚禮無論是「神前式」、「仏前式」或在牧師見證下的宗教儀式, 都比較嚴肅。

傳統上, 中國的新娘裙褂以象徵喜慶的紅色為主, 褂上有金銀線的龍鳳繡, 象徵龍鳳呈祥。西風 東漸, 當下的新郎反而大多選擇西裝而放棄傳統馬补, 新娘和新郎的衣裝, 一中一西, 相映成趣。相 反, 在這方面, 日本人比較堅守傳統, 新娘依然喜歡穿著始自平安時代 (794-1192) 的白色絲綢和服, 白色在中國是哀悼的顔色, 但在日本白色則象徵無垢, 也象徵新的開始。新郎的衣裝方面, 則是傳統 的手持白色折扇，上穿黑色絲綢和服，下穿班紋摺袴。

在賀禮方面, 日本人跟中國人一樣，會給一對新人送上禮金，但日本人對諧音跟「死」和「苦」 一樣的 4 和 9 兩個數字有所忌諱, 所以禮金數目不可能是 4 萬日元或 9 萬日元。有些人甚至認為以 2 除得盡的偶數並不吉利, 因為 2 象徵一對新人, 除得盡在日文來說是「割り切れる」, 容易令人聯想 起分離的「別れる」, 所以也避免送上以 2 除得盡的偶數禮金。不過, 8 則是個吉利的數字, 因為橫寫 的阿拉伯數字 8 跟無限的「少」相似, 是百年好合, 永結同心的象徵。

死是人生最大的無奈, 經過不同時代的洗禮, 中國的葬禮參雜了儒、佛、道各家的色彩, 受限於 客觀環境, 現代人早已將各種繁文縟節盡量簡化, 不過從死亡到下葬還得花好幾個星期, 這跟日本一 般只花三天時間大相逕庭。日本的葬禮莊嚴肅穆, 鮮有呼天搶地, 出席者都會穿上黑色素服, 由於大 多採用佛教儀式舉行, 所以會不斷聽到法師給死者祈福的誦經聲。在瞻仰死者遺容時, 禮儀師會把親 友送來的鮮花剪下, 遞給親友置放於靈殹內的遺體四周陪葬。

追悼會的方式也大異其趣, 中國式的追悼會一般是來賓向與會者述說死者生平或和死者交往的舊 事。日本式的追悼會則是來賓面對死者遺照, 宣讀悼文, 而且悼文的對象是死者。

\section{5. 《趙錢孫李 - 佐藤鈴木》}

最新出版的中國姓氏大辭典 (2010 年 10 月出版) 總共收錄了 23,813 個姓氏, 原來中國人的姓氏以 單字姓和雙字姓居多, 少數民族之中也有些姓氏是三個字、四個字, 甚至五、六個字的。一些以地名 或官職為姓, 如「王」、「李」、「劉」、「陳」等, 也有像顔色似的姓氏, 如「紅」、「黃」、 「藍」、「白」等, 也有像動物般如「馬」、「牛」、「羊」、「熊」等姓氏, 複姓也有「歐陽」、 「公孫」、「司徒」、「南宮」等九千多個。不過, 以人口比例計, 13 億人口的中國遠遠比不上只有 1 億 2 千多萬人口的日本, 1997 年出版的日本苗字大辭典總共收錄了 291,129 個姓氏, 遠超中國。

日本人姓氏之中, 除了「鈴木」、「田中」、「佐藤」等廣為人知的大姓之外, 還有不少例如 
「夏目」(なつめ)、「望月」（もちづき）、「春日」（かすが）、「月見里」（やまなし）、 「寒河江」（さがえ）等帶有詩情畫意的姓氏。不過, 「犬養」（いぬかい）、「猪股」（いのま た）、「野尻」(のじり）、「狗巻」(いぬまき）、「小此鬼」（おこのぎ）、「亀井」（かめ い) 等帶有「猪」、「狗」、「鬼」、「龜」等漢字的姓氏卻令中國人大惑不解。「青鬼」（㧧 き)、「陰地」(おんじ)、「鬼塚」（おにづか）等姓氏更令人不寒而慄。此外, 「色摩」（しか ま）、「延命」（えんめい）、「御手洗」（みたらし）、「一寸木」（ちょっき）、「児子」（に ご）、「下岡」（しもおか）等姓氏也教人會心微笑。四個字的姓氏在日本比較罕見，「四月一日」 (わたぬき)、「百々目木」（どどめき）等也很有創意。

\section{6. 《青出於藍 - 有往有來》}

傳說倉頡造字, 鬼哭魂嚎, 因為有了文字, 會導致民智日開, 民德日離。日本人青出於藍, 也創 造了「峠」、「柛」、「辻」、「㷣」、「㫐」、「凩」、「畕」、「枠」、「井」等一大堆漢字。

日本人吸收了大量中國文化精髓, 佛經之外, 孔孟之道, 孫子兵法、陽明學說等都對日本影響深 遠, 被奉為學問之神的藤原道真更是漢學大師, 戰國時代的著名武將武田信玄也以孫子兵法中的風林 火山來指揮軍隊。日文中不乏好像「一石二鳥」、「雲泥の差」、「破竹の勢い」、「百聞は一見に しかず」、「忠言耳に逆らう」等引用中國經典名句或諺語的例子。

另一方面, 中國人也向日本取經, 晚清以來傳入的日文詞彙, 多如恆河沙數。年輕一代可能不知 道「不景氣」、「場合」、「場所」、「單位」、「發明」、「反對」、「否決」、「國際」、「環 境」、「盲從」、「偶然」、「市場」、「儲蓄」等常見的詞彙都來自日本, 如果抽去這些詞彙, 我 們的造句會是怎麼的一番景象！其實當今大行其道的日文詞彙也有「物流」、「女優」、「援交」、 「放題」、「物語」、「便當」、「玄關」、「親子」等。

\section{7. 《數字感覺》}

似乎任何民族對數字都會有某種特殊感覺, 一些有所忌諱, 一些則有所鍾愛。中國人和日本人也 不能例外。中國人見到 4 字或 14 往往避之則吉。但中國人鍾情的數字二、三、六、八、九, 對日本 人來說也不全都是吉利的象徵。譬如對中國人來說「 $9 」$ 由於跟「久」的發音一樣, 寓意長久, 是個 吉利的數字。但日本人卻認為「9」跟「苦」（<）的發音一樣, 對 9 字大都敬而遠之。此外, 中國 人尤其是廣東人都會喜歡「3 3 」這個數字, 認為象徵生生猛猛。但日本人卻不大喜歡這個數字, 因 為「 33 」 的諧音跟「さんざん」相似, 「さんざん」意為悽慘、糟透了等意思。3 3 歲對女性來說 更是厄運之年, 人生中諸如結婚、創業等重大事情都避免在這厄運之年舉行。對男士來說, 42 歲是 厄運之年, 因為 42 的諧音跟「死に」（去死）一樣, 簡直萬事皆凶。一些地方的日本人更認為在男 士 42 歲一年出生的孩子是厄子, 難以長大, 或長大後也不能成才。按習俗父母會把這個厄子遺棄在 
街上, 再託他人撿拾回來, 象徵把厄運去除。

諧音「易發」的 28 是香港人特別喜愛的兩個數字, 日文唸作「にっぱち」的二八, 是商場上常 見的用語, 表示冷冷清清, 市沉十分差勁的意思。從氣象學來說, 這兩個一冷一熱的月份確實令人寧 願足不出戶, 可能是這個緣故, 很多行業都受到影響。所以, 遇上生意不好的時候, 很多人都會說: 「にっぱちですから悋え」。一些人甚至會託辭：「にっぱちじや、やむをえない。」「にっぱちだ から、どうしようもないんだ。」來拖延給客戶結帳。

\section{8. 《一絲不苟 vs 不拘小節》}

有時日本人一絲不苟的處事態度, 在中國人看來近乎吹毛求疵。在香港某日資公司工作的某君有 過以下的經歷。有一天, 日本人上司著他到銀行去換取好幾張鈔票, 說是作賀禮用的, 並千叮萬囑指 定要全新紙幣。時維中秋, 任何人都知道沒可能在銀行換得全新鈔票的, 某君的任務當然無法完成, 雖然他已經盡量給上司找來摺痕較淺的鈔票, 但最終還是給上司指責為辦事不力。其實, 跟中國人絕 對不會用白色信封作賀禮封包一樣, 賀禮用的紙幣一定要全新的幾乎是日本人的共識, 因為這除了象 徵純潔和新的開始之外, 更重要的是有尊重對方的用意。反之, 粃事用的帛金則絕對不能用全新紙 幣, 因為不能給坆主有預先準備好帛金的感覺。在這種情況之下, 前述的「尊重」似乎不能大派用場 了。就是這樣子, 對錯往往是一線之差, 不明就裡, 很難拿捏得準。

雖然日本歷史上發生過很多次以下犯上, 即所謂「下克上」的謀反事件, 但日本官場和商場依然 十分講究上下從屬關係, 連在會議室、會客室甚至汽車上客人應該坐在哪裡都有慎密的安排, 給客人 奉茶時也得按階級分先後次序。

到過日本旅行的人都很欣賞日本人把廝所打理得十分乾爽潔淨, 事實上, 日本人也常常引此為 傲。除此之外, 日本人也十分講究紀律和秩序, 他們遵守交通燈號、不插隊、不隨地扔垃圾、叫他們 敲三下鐘他們絕不會只敲兩下了事等一絲不荷的生活態度在不少不拘小節的中國人看來是有欠靈活 的。

\section{9.《和而不同》}

一絲不苟的態度從另一個角度來看可能是墨守成規, 不拘小節也可能是不識大體, 文化是隨著生 活衍生出來的群體習慣和生活模式, 包括禮儀習俗、飲食習慣、衣著、語言、文字、音樂、繪畫以至 製造技術、使用工具、信仰、對圖騰的崇拜、思維方式、價值觀等。不同的民族, 生活方式各異, 孰 優孰劣, 不能憑主觀思維作判斷, 得互相尊重, 包容才能減少摩擦, 創造和而不同的世界。 